\title{
ELECCIONES EN SUECIA
}

El 16 de septiembre de 1979 los suecos acudieron a las urnas para elegir sus representantes en los Consejos locales, provinciales y en el Parlamento. Hay que señalar que por primera vez los extranjeros tuvieron derecho de voto por lo que hace referencia a la elección de los Consejos locales.

Desde las últimas elecciones legislativas, celebradas en septiembre de 1976, hasta las de 1979, la vida política sueca se ha caracterizado por una fuerte inestabilidad. Tras la derrota en 1976 del partido socialdemócrata después de cuarenta y cuatro años ininterrumpidos en el ejercicio del poder, una coalición de tres partidos -el denominado bloque burgués, compuesto por moderados, centristas y liberalesestuvo al frente del gobierno durante el período comprendido entre octubre de 1976 y octubre de 1978. La derrota de la propuesta que el entonces primer ministro, el centrista Thorbjor Fálldin, hiciera al Riksdag (Parlamento) - propuesta que tenía como finalidad la paralización del proyecto de creación de nuevas plantas nucleares (programa nuclear iniciado por el gobierno socialdemócrata en 1975 y compuesto por un plan de construcción de doce plantas, de las cuales cinco se encuentran ya en funcionamiento) - tuvo como consecuencia la dimisión del líder centrista, toda vez que aquel objetivo constituía el centro de su programa electoral mientras que moderados y liberales, miembros de la coalición de gobierno, votaron con los socialdemócratas a favor del desarrollo del mencionado plan energético.

Tras la disolución del gobierno en octubre de 1978, el líder liberal Olla Ullster se hizo cargo, con el voto a favor de los centristas, el voto en contra de moderados y comunistas y el apoyo indirecto de los socialdemócratas que se abstuvieron en la votación de investidura, de la formación de un nuevo gobierno compuesto exclusivamente por liberales que han venido ejerciendo sus funciones hasta las elecciones legislativas de 1979.

No obstante, la sensibilidad demostrada por la opinión pública sueca tras el accidente ocurrido en la planta nuclear de Harrisburg (EE. UU.) ha obligado a los partidos políticos a matizar su posición frente a la creación de nuevas plantas. Consecuencia de ello ha sido la convocatoria de un referéndum, a celebrar en marzo de 1980 , en el que se habrá de decidir el futuro que el desarrollo de la energía nuclear haya de tener en el país.

Durante la campaña electoral desarrollada con ocasión de las legislativas de 1979, el problema energético ha sido soslayado sistemáticamente por los partidos, que han adoptado a este respecto una actitud de indefinición. El tema central de la 
campaña ha girado esta vez en torno a la política fiscal, fundamentalmente a propósito de la polémica mantenida por moderados y socialdemócratas sobre la conveniencia o no de la reforma del sistema impositivo, reforma que - defendida por los moderados- habría de perseguir el reforzamiento del impuesto indirecto frente al directo, al que corresponde hoy el mayor peso en el sistema impositivo sueco.

Desde 1906, uno de los primeros países en que fue implantado, rige en Suecia el sistema electoral proporcional. Las elecciones legislativas tienen lugar cada tres años y el Parlamento se compone de una Cámara de 349 miembros desde la reforma que tuviera lugar en 1974 después de la insólita situación creada en las elecciones de 1973. En aquella ocasión, con 350 escaños a cubrir, los bloques socialista y burgués empataron en el número de escaños obtenidos, situación que se resolvió entonces recurriendo al sorteo para decidir la mayoría.

RESULTADOS DE LAS ELECCIONES DE 1979 Y 1976

\begin{tabular}{|c|c|c|c|c|c|}
\hline & \multirow{2}{*}{ PARTIDOS } & \multicolumn{2}{|c|}{1979} & \multicolumn{2}{|c|}{1976} \\
\hline & & $\%$ & Escaños & $\%$ & Escaños \\
\hline \multirow{3}{*}{$\begin{array}{l}\text { BLOQUE } \\
\text { BURGUES }\end{array}$} & $\begin{array}{l}\text { Moderaterna } \\
\text { (Moderados) }\end{array}$ & 20,44 & 73 & 15,6 & 55 \\
\hline & $\begin{array}{l}\text { Centerpartiet } \\
\text { (Centristas) }\end{array}$ & 18,17 & 64 & 24,1 & 86 \\
\hline & $\begin{array}{l}\text { Folkpartiet } \\
\text { (Liberales) }\end{array}$ & 10,64 & 38 & 11,1 & 39 \\
\hline \multirow{3}{*}{$\begin{array}{l}\text { BLOQUE } \\
\text { SOCIALISTA }\end{array}$} & $\begin{array}{l}\text { Socialdemrocraterna } \\
\text { (Socialdemócratas) }\end{array}$ & 43,48 & 154 & 42,7 & 152 \\
\hline & $\begin{array}{l}\text { Vaenterspartiet komunisterna } \\
\text { (Comunistas) }\end{array}$ & 5,63 & 20 & 4,8 & 17 \\
\hline & Total & 98,36 & 349 & 98,3 & 349 \\
\hline
\end{tabular}

1 Los datos han sido facilitados por la Embajada de Suecia.

Otros dos partidos políticos presentados a las elecciones y situados a la izquierda de los comunistas no consiguieron representación parlamentaria, alcanzando entre ambos un 1,64 por 100 de los votos.

Tras los resultados de las elecciones legislativas de 1979 cabe observar lo siguiente:

- El desplazamiento de votos producidos dentro del bloque burgués. El 6 por 100 de votos perdidos por los centristas lo ha sido en beneficio fundamentalmente de los moderados, que consiguen aumentar en un 4,8 por 100 , mientras que los liberales descienden ligeramente con una pérdida de un 0,5 por 100 .

- Cierta recuperación del bloque socialista a pesar de no haber alcanzado la mayoría por un escaño de diferencia -174 frente a $175-$. Los socialdemócratas progresan en un 0,8 por 100 y reencuentran su nivel de 1973 . La socialdemocracia probablemente ha resultado beneficiada en alguna medida por la fuerte caída del partido centrista. Los comunistas, que aumentan igualmente en un 0,8 por 100 , consiguiendo en esta elección los mejores resultados en treinta años, sin duda se han visto electoralmente beneficiados por 
la escisión de 1977 que trajo consigo el abandono del partido por parte del ala promoscovita.

- La falta de incidencia que el problema nuclear ha tenido en la elección de los votantes - puesta de manifiesto en los resultados obtenidos por los centristas, máximos opositores al desarrollo de la energía nuclear-, aunque sería muy arriesgado pronosticar a partir de ahí un resultado favorable al desarrollo del actual plan energético en el referéndum de marzo del próximo año.

- Por último, hay que señalar la existencia de importantes dificultades para la formación de un gobierno estable, toda vez que el corrimiento de votos en el seno de la coalición burguesa, con el importante avance de los moderados, pondría en situación de dependencia a centristas y liberales a la hora de determinar la política del país. Por lo que hace referencia en especial al partido centrista, existen importantes bases de desacuerdo, fundamentalmente en materia fiscal y energética, entre el mismo y el partido moderadc. Por otra parte, el partido socialdemócrata no apoyaría esta vez a los liberales como hiciera tras la crisis de gobierno de 1978.

Muy significativas de los problemas planteados en la vida política sueca después de estas elecciones nos parecen las palabras del líder socialdemócrata Olof Palme, quien declaró el 19 de septiembre:

«No cabe pensar en la colaboración con los centristas o los liberales. Estos últimos han vuelto imposible todo acercamiento al arrojarse en brazos de una derecha cada vez más agresiva, de la que se han convertido en prisioneros. El empuje de la derecha en Europa del Norte ha de ser terminantemente contrarrestado mediante una lucha ideológica.»

En suma, el resultado de las elecciones legislativas de 1979 en Suecia viene a confirmar en términos electorales la existencia de una crisis profunda (de la que serían asimismo indicio los respectivos avances de moderados y comunistas), cuyas primeras manifestaciones han tenido lugar a lo largo de estos tres últimos años y cuya causa, al menos inmediata, habría que buscar en la conmoción producida por la crisis energética mundial, de la que no parecen verse excluidos los presuntos modelos de estabilidad socioeconómica y política como el sueco.

Pilar del Castillo Vera 